\title{
Intersectional Criminologies for the Contemporary Moment: Crucial Questions of Power, Praxis and Technologies of Control
}

\author{
Kathryn Henne ${ }^{1,2} \cdot$ Emily I. Troshynski ${ }^{3}$
}

Published online: 19 March 2019

(c) Springer Nature B.V. 2019

\begin{abstract}
This article reflects on the growing acceptance of intersectional criminology alongside emergent challenges of the contemporary moment. In light of social changes, the article asks: What is important about intersectionality and its relationship to criminology? How might we sustain and nurture these crucial dimensions and connections? Exploring answers to these questions, we consider how to retain intersectional commitments in areas of increasing importance, such as ubiquitous surveillance and technologies of policing. In discussing how we might examine and unpack the workings of interlocking systems of oppression and their effects, this article addresses how intersectional criminologists might reflect more critically on their methodologies to ensure robust analysis and incorporate frameworks that better capture the technosocial entanglements emblematic of ongoing shifts in social control. After reviewing approaches for doing so, the article concludes with a reflection on implications for intersectional criminological praxis.
\end{abstract}

\section{Introduction: Taking Stock at Critical Junctures}

In recent years, the rise of authoritarianism in various parts of the world has been met with protest movements, as well as calls for inclusion, mobilization and resistance. Rightfully so: in the United States (US) alone, the Trump administration has signaled its support for establishing a registry to track Muslims, attempted to enact a federal ban against transgender persons serving in the US military, and committed significant resources to enhancing surveillance infrastructure aimed at racialized minorities. ${ }^{1}$ All the while, anti-immigrant, anti-Semitic, homophobic, Islamophobic, misogynistic, racist, and sexist attacks have risen since the 2016 US presidential election (Southern Poverty Law Center 2016). In this

\footnotetext{
1 Following Hochman (2018), we use "racialized" to acknowledge that individuals, groups, and structures become racialized through worldly processes, not as a result of their inherent attributes.

Kathryn Henne

khenne@uwaterloo.ca

1 University of Waterloo, Waterloo, ON, Canada

2 The Australian National University, Canberra, ACT, Australia

3 University of Nevada, Las Vegas, USA
} 
political climate, intersectionality has emerged as a foundation for progressive collective action: commentators present it as an influential paradigm for activism (Nash 2019) and a "necessary evolution in criminological theory" (Potter 2013: 306). The "now familiar mandate that 'if your feminism isn't intersectional, it's bullshit", suggests "that intersectionality has become a kind of article of faith" (Nash 2019: 16). Not only is intersectionality a cornerstone of women's studies, ${ }^{2}$ it has also proliferated across disciplines.

Criminology is one such discipline. Intersectional criminology "necessitates a critical reflection on the impact of interconnected identities and statuses of individuals and groups in relation to their experiences with crime, the social control of crime, and any crime-related issues" (Potter 2013: 305; see also Henne and Troshynski 2017). It builds upon a hallmark of intersectionality: the widespread recognition that "the violence that many women experience is often shaped by other dimensions of their identities such as race and class" (Crenshaw 1991: 1242). Intersectionality, once associated primarily with the nexus of class, gender and race, is better understood as a "broad, open-ended and inclusive conceptual tool for feminist analysis" (Lykke 2011: 209, quoted in Potter 2013: 309). As Potter (2013) emphasizes, the concept is rooted in a longer genealogy of Black feminist intellectual thought, which has shaped its commitments to anti-essentialism and to addressing multiplicative dimensions of inequality and oppression. As such, intersectionality is often thought of as a more holistic approach to documenting and thinking through how authority, domination and power coalesce in lived human experiences, even though some scholars argue that its focus on relationships between identity and experience renders it ill equipped to capture disciplinary practices of enabled through technologies of control and surveillance (Puar 2007).

In this article, we reflect on the promises and possibilities of intersectional criminology alongside noted critiques. First, however, we must contextualize our observations by attending to expressed concerns about the unintended effects of intersectionality's popularity. Nash (2019: 4) argues that "intersectionality's ubiquity in women's studies is often taken as evidence of how Black feminism has transformed the discipline" of women's studies, supporting a larger "progress narrative" that depicts women's studies as having "overcome its past exclusions" by "refus[ing] so-called White feminism." Nash cautions that the lived experiences and practices underscoring progress narratives might not reflect the changes they purport, as hegemonic forces inform the dynamics that materialize on the ground. Against this backdrop, such narratives can actually hinder broader transformation. As Crenshaw (1988: 1385) explained over 30 years ago in relation to civil rights, signs of progressive social change can "undermine the ability to move forward toward a broader vision of racial equality." Rights and recognition alone do not ensure structural change. The celebration of victories, such as the passage of anti-discrimination laws, may "counter some of the most repressive aspects of racial domination" (Crenshaw 1988: 1370), but, consequently, they can draw critical attention away from how liberal ideologies perpetuate myths about better opportunities and material gains for racialized groups. Crenshaw's words thus offer important reminders when reflecting on the extent to which the embrace of intersectionality has changed fields of inquiry.

In the context of criminology, the promotion of intersectionality's transformative potential purports a progress narrative that continues to gain traction. For example, more abstracts at the 2018 annual meeting of the American Society of Criminology (ASC)

\footnotetext{
2 Nash (2019) uses "women's studies" to delineate the "interdiscipline"- - a term that Binder (1987) employed to describe criminology - that is also referred to as "feminist studies," "gender studies," "gender and sexuality studies," and "women's and gender studies." We use her terminology in the interests of consistency, not to suggest the field is limited to the study of women.
} 
referred to intersectionality (87) than to the following mainstays of criminological analysis: randomized control trials (55), mass incarceration (57), gangs (69), and life course (81). The annual meeting also included a thematic panel entitled, "Celebrating 20 years of Black Women's Contributions to Criminological Thought," which featured prominent Black scholars, Delores Jones-Brown, Helen Greene, Hillary Potter, Katheryn Russell-Brown, and Vernetta Young. ${ }^{3}$ The panel showcased and celebrated these scholars' collective work (for example, Gabbidon and Greene 2018; Jones-Brown 2000; Potter 2015; Russell-Brown 1998; Young 1986) in explicating gendered and racialized dimensions of criminological inquiry, and underscored their affective, embodied, and political labor in the discipline of criminology and beyond-labor that is often ignored in the academy (Hong 2008; Nash 2019). These events and celebrations mark important developments in criminology, especially given Daly's comment that, "intersectional analyses are more an aspiration for the future than a research practice [in criminology] today" (2010: 237). Importantly, we see a broader awareness of the interconnections between multiple formations of oppression as they pertain to crime, criminal justice, and conceptualizations of deviance. In light of these shifts, we think it timely to reflect on the following question: What is important about intersectionality and its relationship to criminology? How might we sustain and nurture the crucial dimensions of intersectionality and its connection to criminology, while being attentive to hegemonic shifts in criminology, the academy, and politics? Given the widespread support for intersectionality as a necessary foundation of political coalitions and scholarly analyses, we would be remiss not to consider the extent to which intersectional criminology responds to changing structures of social control.

This line of questioning prompts us to revisit critiques of what intersectionality misses when it focuses primarily on individuals' identities and lived experiences (e.g., Puar 2007) and to consider its relevance for emergent issues of crime, deviance, and social control. To illustrate our point, we focus our attention on issues with which intersectional criminology has yet to grapple: practices of "materialization," which are central to a large body of interdisciplinary literature in Science and Technology Studies (STS) and feminist technoscience $^{4}$ that considers how individual actors-human, technological, or otherwise-are not necessarily pre-existing entities that prompt or generate change but instead emerge via entangled relations (see Barad 2007; Haraway 1991). The materialization of technosocial relations is especially important for criminological inquiry in the contemporary moment. For instance, Alexander (2018) has argued recently that new criminal justice reforms constitute the "newest Jim Crow" by supporting the spread of "e-incarceration," which employs algorithmic, risk assessment, and surveillance technologies to determine "who should be caged and who should be set 'free'." These developments evidence shifting modes of control that not only have a disproportionate impact on vulnerable populations, but are also part of infrastructures that exceed the scope of traditional intersectional analysis. Our concern is that the tendency to prioritize identity-based approaches may present classist, debilitating, gendered and racialized practices as static features, thereby losing sight of the entangled relations that enable their materialization in the lived experiences of persons who occupy marginalized positions in society. By doing so, the celebration of intersectionality might contribute to a progress narrative that advances critical race

\footnotetext{
${ }^{3}$ We thank Jenna Imad Harb and Rita Shah for their perspectives on the significance of the event.

4 This framing of science and technology focuses on the material-semiotic dimensions of practice and thus requires attention to how both are co-constitutive and historically situated.
} 
theoretical advancements in criminology, but also directs scrutiny away from other insidious vectors of oppression.

This article proceeds in four parts. We begin by reflecting on common articulations of intersectionality, particularly in relation to criminology. Next, we outline potential shortcomings and misappropriations of intersectional criminology, followed by an overview of how we might begin to take materialization seriously while retaining intersectional political commitments. In discussing materiality, we incorporate insights from feminist technoscience, as we both draw on this field in our independent and collaborative research (e.g., Henne 2014, 2015; Henne and Troshynski 2013b; Troshynski 2017; Troshynski and Weiner 2016). We do, however, acknowledge criticisms that the larger debate around "intersectional theorizing" tends to "let White feminists, especially those working on technoscience and (new) materialism off the hook and, quite frankly [has] burdened women of color theorists and activists" (Puar 2017: 20-21). We therefore highlight infrastructures of control in which human and nonhuman actors feature centrally and emphasize that their intersectional contours do not disappear. If anything, they become manifest in forms that exceed traditional notions of bodies and identities, taking on ontological dimensions that require further interrogation. With these considerations in mind, we conclude with a discussion of the implications for an intersectional praxis.

\section{Intersectional Criminology (As We Think We Know It)}

Scholars have employed intersectionality to shed light on power structures and interrelated systems of oppression (Collins 2000), differences between and among groups (e.g., King 1988; Purdie-Vaughns and Eibach 2008), and how law and regulation disproportionately affect populations along intersecting social categories of difference (e.g., Dottolo and Stewart 2008). Intersectionality's widespread appeal has meant its extension into areas beyond its earlier focus on gender and race (Black women's experiences, specifically) and applications to antidiscrimination law (see Crenshaw 1988, 1991). In this respect, one could argue that intersectionality has become mainstreamed in women's studies and beyond (May 2015). It has brought about greater awareness of the limits of law and its "additive" approach to discrimination on the basis of gender or race- a flawed understanding that frames discriminatory practices as if they are suffered by racialized men and White women, making inequalities experienced by racialized women invisible (see Crenshaw 1991). Intersectionality has illustrated that attempts to distinguish "Blackness" or "womanhood" as specific forms of oppression inevitably construct identities in essentialist ways and re-inscribe misguided assumptions about the experiences of people who are members of marginalized groups (Yuval-Davis 2006).

Mainstreaming can have unexpected effects. While intersectionality has brought about a broader recognition of the nuanced ways that social divisions are constitutively constructed, it has also "been weakened within the contemporary academy" (Collins 2015: 6). For example, even though class is an axis of marginalization mentioned routinely in intersectional scholarship, it "remains underutilized as an analytical category to explain complex social inequalities" (Collins 2015: 13). Further, as Carbado (2013: 817) notes, the entrenchment of normative identities remains problematic, with the role of Whiteness largely "invisible or unarticulated as an intersectional subject position." These individual observations point to a larger pattern that Charlesworth (2005: 13) explains in the relation 
to gender mainstreaming and human rights 5 - that widespread uptake of a corrective lens meant to support progressive practice "can quickly become a token exercise" rather than the more robust practice of thoughtful consideration and implementation. The idea of appealing to the mainstream, she explains, is "after all, a conservative one," and broader transformation "can be undermined by general structures of power" (Charlesworth 2005: 18). Nash (2019: 3-4) traces similar dynamics playing out institutionally in academia: women's studies - a field that claims to reflect intersectional commitments - "is organized around the symbol of Black woman even as the field retains little interest in the materiality of Black women's bodies, the complexity of Black women's experiences, or the heterogeneity of Black women's intellectual and creative production." In practice, Nash argues, the field actually maintains "an ambivalent relationship with the analytic" of intersectionality (2019: 2).

In contrast, an intersectional criminology, according to Potter, should not be tokenistic, as it is committed to "assess[ing] the salience of identities and statuses" of "individuals and groups in relation to their experiences with crime, the social control of crime, and any crime-related issues" (2013: 316). Potter traces a lineage of criminological work with intersectional sensibilities to research published as early as Visher (1983), which was attuned critically to distinctions in Black women's experiences of arrest. Potter also makes clear that "intersectionality theory is strongly tied to real-world activism" (2013: 314), thereby linking criminology with "intersectional feminist praxis" (Naples 2009: 574) in terms of its valuing of experiential insights in shaping theory, as well as its commitments to reflection, action, and accountability.

To date, much of the intersectional criminological scholarship focuses on documenting how power operates via systems of justice, attending to multiplicative axes of marginalization and their effects as documented through lived experience. Specifically, as outlined by Creek and Dunn (2014), researchers have incorporated an intersectional lens to understand how violence against women interconnects with race and class (e.g., Josephson 2002; Richie 1996; Sokoloff 2004), as well as with ethnicity and immigration status (e.g., Erez et al. 2009; Singh 2010). In Critical Criminology: An International Journal alone, articles employing intersectionality have explored its application in the advancement of activism, methodology, and various subfields of critical criminology (e.g., Carrington et al. 2014; Potter 2013; Trahan 2011). Intersectional criminology has also encouraged deeper analysis of the ways in which power operates in light of social change. Arrigo and Bersot (2016: 552), for instance, note how struggles for identity offer an opportunity to examine how "relations of power react to the hierarchy (i.e., oppose oppression) in ways that often reconstitute a new or different one in the very act of negating the other's unjust control." This critical attention to power is a key reason why Belknap (2015) posits intersectional criminology as foundational to an "activist criminology" that pursues legal and social justice across spaces of teaching, research, outreach, and policy.

Given its emphasis, intersectional criminology should be well positioned to offer alternatives to feminist and criminological interventions that have contributed to legislation that supports carceral expansion and punitive enforcement (e.g., Bernstein 2010; Musto

\footnotetext{
5 The practice of "mainstreaming a gender perspective," which is often referred to as "gender mainstreaming," is meant to incorporate women-centered perspectives and gender-sensitive research to enhance policy implementation (Association for Women's Rights in Development 2004). Such strategies aim to achieve gender equality yet are recognized as encapsulating "many of the tensions and dilemmas in feminist theory and practice" (Walby 2005: 321).
} 
2016 this issue). Formal legal interventions often enhance "the powers of the punishing state to capture more bodies" and "fail[] to address the structural violences enacted by the state, particularly those of White supremacy," because, as Whalley and Hackett (2017: 4) explain, "the state itself enshrines White supremacy, heteropatriarchy, and transmisogyny into its legal codes - a structure that operates through nonconsensual imposition, coercion, and at many times, brute force." State interventions invite the possibility of reinforcing intersectional inequalities, even as they are upheld as responding to intersectional demands. As Williams (2008) illustrates in the Canadian context, the incorporation of intersectionality into legal processes has not reduced the incarceration of Indigenous women (which has, in fact, continued to increase). While the recognition of complex identities and experiences may aid in keeping Indigenous women in their communities, it has also factored into decisions that support incapacitation and punishment. Thus, bringing attention to intersectional identities does not necessarily counteract or correct for legalized state violence or racism.

Revisiting concerns around how technology can extend the carceral arm of the state, including the rise of e-incarceration, offers another case in which well-intended provisions have supported the development of infrastructures of control. In-depth research by Eubanks (2018) documents the role that new technologies have played in welfare provision in the US, revealing that the increased reliance on tools for monitoring compliance and for assessing and predicting risk has meant that already marginalized people are surveilled more closely than other citizens and therefore become prone to punishment and criminalization. These arrangements, according to Monahan (2017: 193), facilitate moral assessments that underscore "the stigma of being on welfare" and "suspicion of deficiencies with one's character." Focusing on these dimensions alone, however, does not provide a comprehensive picture of the regulatory systems at work, which are shifting in at least two key ways: (1) they are increasingly exercising explicitly structural power via information technologies, surveillance infrastructure, and their combined net-widening effects; and (2) they are enhanced by architectures of control that are now part of everyday life.

A key challenge for researchers is that the scope of these systems of control is not fully visible to onlookers or to the persons who must navigate them. How, then, do we, as critical criminologists, unpack the discriminatory nature and effects of these infrastructures, especially when they do not appear as such on the surface? How do we cultivate and promote an intersectional sensibility when interrogating changing technologies of control? Doing so first requires considering other critical interventions around how we traditionally think about intersectionality.

\section{An End of Intersectionality (As We Thought We Knew It)?}

While the growing body of intersectional criminology makes important inroads regarding how power operates in everyday life and in processes of criminalization, there are potentially overlooked dimensions of intersectionality in practice, more generally, and in criminological research, specifically. Intersectionality's focus on identity has clear theoretical and activist purchase, but this may be part of its limitations. Just as intersectionality has brought about needed attention to overlapping and conflicting dynamics of difference, inequalities, and marginality, it has also been "misconstrued... in ways that uphold single-axis thinking, rather than align with its matrix orientation" (May 2015: ix). In doing so, the widespread embrace of intersectionality may not necessarily deliver on its promise 
of exposing how "single-axis thinking undermines legal thinking, disciplinary knowledge production, and struggles for social justice" (Cho et al. 2013: 787).

Criminological research that depicts social categories of social difference in ways that contribute to their naturalization as distinct factors is deserving of this critique. This tendency is perhaps most evident among statistical analyses that claim to use an "intersectional framework" (e.g., Bell 2017; Parker and Hefner 2015) ${ }^{6}$ but often sideline robust intersectional analysis in favor of reporting on the combined influence of identity-related variables or showcasing comparisons across variables and their effects on criminological phenomena (and vice versa) (see Creek and Dunn 2014). Try as some might, it can be difficult for quantitative scholars to escape the "additive assumptions" that intersectionality tries to refigure, especially given positivist goals of isolating specific dynamics to explain causality (Bowleg 2008: 322). In noting the tensions between essentializing categories and attending to statistically significant patterns, Barak and colleagues (2010: 137) highlight how this point is relevant for criminologists: they often cannot specify under what conditions particular categories will take precedence, or in what form(s), because "crosscutting social relations" inherent to complex sociality yield multiple meanings, interpretations, experiences, and implications. Even though scholars have cautioned that quantitative methodologies are often ill-suited for capturing the dynamic and relational dimensions of intersectionality (e.g., Henne and Troshynski 2013a; Trahan 2011), journals and studies that promote these analyses are on the rise. ${ }^{7}$

In light of these developments, criminologists might benefit from earlier scholarly reflections on how to refine their methodological toolkits so that they are more likely to work in the service of intersectional aims. McCall (2005) suggests several approaches for crafting intersectional methodologies. The first, "anticategorical complexity," is useful in deconstructing categories that render the complexity and multiplicity of human experience invisible, because it illuminates the social processes of categorization that reinforce hierarchies that sustain oppression (McCall 2005: 1773-1776). The second, "intracategorical complexity," explores marginalized identities to expose and problematize assumed similarities within groups that under-theorize experiences of a multitude of persons. Moreover, in problematizing the exclusionary acts of categorization, "anticategorical complexity" enables the deconstruction of accepted categories. "Intercategorical complexity" exposes the relationships between inequality and the categories themselves, but it first requires adopting "analytical categories to document relationships of inequality among social groups" and tracing "changing configurations of inequality along multiple and conflicting dimensions" (McCall 2005: 1786). Suggesting the use of "interaction effects - or multilevel, hierarchical, ecological, and contextual modeling" to "introduce more complexity in estimation and interpretation," McCall notes that these analyses are more advantageous than additive linear analyses (2005: 1778). Others, such as Simpson and Gibbs (2006), argue that mixed methods constitute a better approach: the inclusion of a qualitative component enables bringing out nuances of observed processes and giving

\footnotetext{
6 We do not mean to suggest that all quantitative research undermines intersectionality because such work can aid in rendering structural intersectionality more visible. We do, however, believe positivistic training does not provide adequate preparation for carrying out intersectional analysis. The academic division of labor between quantitative and qualitative research methodologists, which is common in criminology, exacerbates these issues.

7 We should note that there are many qualitative studies that are not attentive to intersectional concerns. We mention quantitative research because of its privileged status in criminology and the clear challenges of capturing dynamic (yet alone multiplicative) social processes using positivistic methods (see Lynch et al. 2017).
} 
voice to research participants, which aids in formulating interpretations that are not imposed by researchers alone. These observations align with Crenshaw's (1991: 1299) point that the distinguishing feature of intersectional methodology is the ability to "speak against internal exclusion and marginalization" in order to challenge institutions and political projects that have silenced voices of those who have been rendered invisible.

Our desire to promote robust intersectional methodologies is admittedly rooted in a deeper, epistemological apprehension. Intersectionality "seems to risk misrecognition on nearly every front, whether co-opted by the state, corporatized in the neoliberal academy, or regulated by feminists committed to intersectionality but who inadvertently norm it to disciplinary logics, methodological conventions, or gender-primary theoretical premises" (May 2015: 95). The fact that criminology is an interventionist field exacerbates these risks, as the knowledge it generates is particularly susceptible to being co-opted and deployed by the state (e.g., Britton 2000; Lumsden and Goode 2018; Walters 2003). As Hudson (2000: 177) argues, criminology "of all the applied social sciences... has the most dangerous relationship to power," because it provides concepts and categories that inform "strategies of control and punishment," which "have implications for the life-chances, for the opportunities freely to move around our cities, and for the rights and liberties of those to whom they are applied." To illustrate using an example related to technology: Shelby (2018a) has traced how the widespread promotion of the rape kit does not resolve challenges in seeking legal justice for women who have experienced sexual assault. The rape kit, she explains, is a feminist intervention imbued with criminological positivism, which advocates hoped would counter gendered biases by offering a reliable and objective tool for collecting evidence. Having not delivered on those promises (see Campbell and Fehler-Cabral 2018; Quinlan 2017), its use fails to attend to-and actually obscures - "other persistent problems in criminal justice responses to sexual assault, such as ignoring how gender norms lead to a broader de-prioritization of rape cases in the criminal justice system" (Shelby 2018a: 5). In short, the materialization of technological solutions cannot be disambiguated from social conditions.

As technological interventions, such as the rape kit, are part of wider transformations, we revisit a reminder expressed by Yuval-Davis (2011: 162-166): careful intersectional scholarship reconsiders shifting "orders of stratification" operating at global, national, and local levels. The next section applies her advice to the technologization of regulatory and criminal justice systems. As feminist surveillance studies scholars argue, such practices have become "integral to many of our foundational structural systems, ones that breed disenfranchisement, and that continue to be institutionalized" (Dubrofsky and Magnet 2015: 7). Thus, while we acknowledge the importance of accounting for the complexities of identities and their formation, we want to draw greater attention to changes that surpass identity-focused frameworkswhich arguably fit within the purview of structural intersectionality and its emphasis on the role of macro-level and institutional contributions to disadvantage. In our earlier work (Henne and Troshynski 2013a), we point to Jasbir Puar's (2007: 211) alternative framing to intersectionality - that is, as assemblages of "dispersed but mutually implicated and messy networks" of social categories - as a starting point for exploring more dynamic modes of analysis. The following pages extend our previous arguments about how to preserve an intersectional awareness when studying social forces as networks. 


\section{Taking the Materialization of Social Control Seriously}

Reflecting on how intersectionality enables consideration of various formations of marginalization, Potter (2013: 306) outlines the "materialization of intersectionality theory" by tracing foundational ideas and texts, as well as their relevance to criminological inquiry. This section of our analysis adopts a different approach: it focuses on how we might consider the aforementioned concerns and critiques of intersectionality alongside insights about materialization as evidenced in relation to technologies of control. By this, we mean the acknowledged importance of "how 'matter' is thought and constituted through entanglements between human and non-human bodies, affects, objects, and practices" (Fullagar 2017: 248). ${ }^{8}$ Paying critical attention to materiality requires a "more-than-human orientation," which attends to actions and actors often discounted by human-centered studies (Fullagar 2017: 253). To explain, we first discuss the importance of asking, "how matter comes to matter" (Barad 2003: 829, emphasis added) before relating these insights to intersectional criminology.

Questions of materialization are central to feminist technoscience, which is a diverse field that explores technosocial relationships manifest vis-à-vis physical objects, institutions, symbols, and identities (Wajcman 2010). ${ }^{9}$ Rather than assume autonomous actors interact to cause effects, many scholars examine how phenomena materialize iteratively in practice. In other words, agency does not precede engagement; agencies emerge through engagements (Barad 2007; Mol 2002). Attending to context alone cannot explain meanings around actors and objects because "entities are brought into being, they are realized in the course of a certain practical activity, and when that happens, they crystallize, provisionally, a particular reality" (Woolgar and Lezaun 2013: 323-324, emphasis added). Framed in this way, there is no shared reality; realities are instead multiple, "complex, non-coherent, uncertain, and in interference with one another" (Law 2004: 5). Although there are critiques of STS's enduring failures to incorporate intersectionality, feminist technoscience has a history of employing intersectional lenses that "avoid generalized or homogenizing conclusions about gender and technology" (Kennedy 2005: 484; see also Moser 2006).

In terms of alternative possibilities for intersectional criminology, we have highlighted how adaptations of assemblage (Henne and Troshynski 2013a), particularly as put forth by Puar (2007), enable the productive scrutiny of a "multiplicity of heterogeneous objects, whose unity comes solely from the fact that these items function together, that they work together as a functional entity" (Patton 1994: 158). Assemblages, themselves contingent, materialize via events and encounters. They are not fixed, permanent or stable, nor are they straightforward. With this framing in mind, Puar (2017) questions intersectionality's reliance on the allegory of women standing at the intersection of different axes (e.g., class, disability, ethnicity, gender, nationality, sexuality), contending that it can reify and stabilize identity categories instead of scrutinizing the dynamism of the forces at work and how they come to interact. ${ }^{10}$ Her criticism is not a full rejection of intersectional commitments

\footnotetext{
8 Acknowledging Ahmed's (2008) criticisms of "new materialism," we refrain from using the term. Specifically, she argues recent feminist materialist critiques often disregard the important ways that poststructural analyses have examined constitutive relationships between the substantive and the discursive.

9 Feminist technoscience does not limit its inquiry to areas in the so-called Global North or to practices deemed modern. Wacjman (2010), for example, acknowledges that Indigenous women are among the first peoples to innovate in a technological sense.

10 Puar (2017: 172) also warns that a focus on matter may seek to disrupt the dominance of linguistic explanations of power, but that there is a danger that doing so might "privilege an essentialist truth produced through matter."
} 
per se; rather, it is a call to reconfigure intersectionality's articulation of questions around identity, politics, and structure to those that "address the constant ontological reassembling of power and its effects" (Puar 2017: 21, emphasis added). In other words, it destabilizes accepted human-centered notions of identity and embodiment.

Studies of surveillance have embraced the assemblage as a productive analytic (Haggarty and Ericson 2000). Surveillance, the widespread practice of social sorting that now entails intrusive modes of collecting and aggregating information on various populations (Lyon 2003), relies increasingly on technologies, rendering a range of non-human actorsboth visible and nonvisible-ubiquitous in our everyday lives. Mechanisms of social control, too, rely on the monitoring of human bodies through the collection and analysis of data that reflect categories, appropriations, and representations of human experiences. The resulting data become the foundation for making behavior measurable, often serving as the basis for constructing "reliable" representations of crime problems and predicting their future trajectories. Accordingly, assessments using data analytics are not based on the actions of the physical (human) body; rather, they rely on sets of variables factored into calculations that can be framed and used in specific ways, such as to influence or anticipate the actions of certain populations.

Take, for instance, technological systems that incorporate personal information mined from numerous sources for use in decision-making processes, which affect prospective home buyers, university students, welfare recipients, and criminal suspects, among others (e.g., Henne and Troshynski 2013b; Eubanks 2018). These technosocial regimes embody ways of seeing and knowing the world that minimize individual complexity, which facilitate regulatory practices that implicate human realities and capacities for living (e.g., distribution of rewards and benefits) and acting (e.g., punishment, resistance, costs). Consider, then, Brayne's (2017) research, which explores how data analytics have both amplified and transformed police surveillance operations. It illustrates how predictive policing, which is perceived as being based on objective measures and tools, "may justify the over-policing of minority communities and potentially take away resources from individuals and areas invisible to data collection sensors or subject to systematic underreporting" (Brayne 2017: 998). Thus, changing policing strategies more than increase and deepen surveillance practices aimed at communities already rendered suspect by authorities; they can further entrench existing perceptions of racialized criminality and contribute to the continued retraction of resources from communities.

As assemblages, criminal justice practices enabled by surveillance can grow and fissure in different directions, generating new modes of monitoring and sorting subjects, extending into new domains and locations, and rendering more populations visible to the gaze of legal and regulatory authorities. For example, surveillance cameras placed in public spaces can transmit data digitally, which state and national law enforcement entities can use to triangulate with other data in efforts to identify, monitor, and investigate persons of potential interest. Critical examinations of the possibilities, risks, and dangers of data-driven criminal justice practices are nascent (e.g., Brayne 2017; Hannah-Moffat 2018), but analyses attuned to intersectional dimensions provide reason for alarm. Magnet's (2011) analysis of biometric authentication by border security, prisons, and welfare agencies attests to the fact that technosocial failures are inevitable. Such technologies fail to reproduce and verify bodily characteristics accurately or reliably, and they deepen social exclusion among populations whose bodies do not fit the normative ideals of the scientists who design them: "biometric technologies that rely upon erroneous assumptions about the biological nature of race, gender, and sexuality produce unbiometrifiable bodies," imagining individual bodies "as stable entities that can reliably give us definitive proof of identity" (Magnet 2011: 
151, 150). In sum, data-driven policing practices, biometric or otherwise, are far from neutral technologies in that their enactment inevitably channels encoded normative values and beliefs, which often materialize in ways that change the observable effects of difference on the ground.

We do not mean to suggest that technosocial relationships are necessarily deterministic. Lupton (2016: 1) explains that "digital data-human assemblages" take shape in everyday life; data become "lively" and are enabled, as well as informed, by active embodied practices. Assemblages are not simply modes of obtaining and utilizing data about people; people also "learn from the assemblages of which they are a part" (Lupton 2016: 2). Data-human engagement is inevitable in many cases and yields more than data for the purpose of coercion. For Lupton (2016), these relationships foster mutual learning by living together, making data possible companions, not simply foes. She-like Haggerty and Ericson (2000) and Brayne (2017) — provides little insight, though, into how to capture and respond to asymmetrical power relations fostered by data-digital assemblages.

In contrast, Eubanks (2018) offers a clear example in which discrepancies in power cannot be ignored. She documents how governments' embrace of automated systems have yielded incorrect judgments, based on errors in data collection and analysis, which have life-threatening implications for those who rely on social services. She explains how social assistance recipients become entangled in the fabric of these networked schemes, constituting a "digital poorhouse" that is woven together by fiber-optic strands (Eubanks 2018: 175-190). In other words, the surveillance of those most in need of services enables the threads of a networks assemblage to wrap more closely - and potentially more tightlyaround them. Just as importantly, while individual circumstances may change or there may be errors in the information obtained by welfare agencies, the data harvested do not necessarily change or disappear accordingly. The imprint may remain hardwired as part of the assemblage.

Data collected about social assistance recipients can render them hypervisible to the gaze of authorities, especially compared to other citizens who do not have their data harvested and cross-checked by other surveillance systems on a regular basis. Through repeated engagements and performances, their activities become documented, stockpiled, searched and corroborated to make an empirical basis for understanding people's lived actions and behaviors. Each of our individual and collective activities, in turn, produces a record that contributes to a "data double: the electronically visual or documentary trace of ourselves that we leave behind in our encounters" (Haggerty and Gazso 2005: 1717). Although not embodied physically, data doubles figure in intersectional processes. Browne (2010, 2015) describes the racializing dimensions of these enactments as digital epidermalization, discussing technological monitoring, particularly biometrics, as enacting a kind of "raceless racism." Specifically, data doubles that depart from a presumed White prototypicality can "do the work of alienating the [racialized] subject by producing a 'truth' about the body and one's identity despite the subject's claims" (Browne 2010: 135). In other words, the very generation of data (and data doubles) can increase the vulnerability of human actors.

As the aforementioned examples illustrate, these enactments can yield the loss of social assistance support for acts assessed algorithmically as noncompliant or targeting by other forms of state control, including, but not limited to e-carceration (Alexander 2018). In fact, as Noble (2018) reminds us, algorithms enable new kinds of racial profiling-what she refers to as technological redlining — which can take on visible and invisible contours in everyday life. According to Noble $(2018: 1,14)$, the important questions around algorithms are unveiling how "digital decisions reinforce oppressive social relations" and "what values 
are prioritized in such automated decision-making systems," especially as the private providers increasingly deliver information services "previously thought of at [part of] the public domain." For her, identity still matters, but in new ways, especially now that it can be bought and sold on the web. These digital entanglements can generate varied and uneven "processes of social stratification," even though they do so under the guise of being valuefree and objective (Magnet 2011: 150).

As intersectional criminology has, for the most part, not yet interrogated technologies of control in practice, we have limited insights into intra-group differences in terms of how these new forms of governance are experienced and how they contribute to the materialization of divergent realities among women and racialized groups. Shelby's (2018b) ongoing research on rape kits stands out as one exception: it sheds light on the intersectional contours of how rape kits have failed to deliver legal justice for Black women by illuminating how authorities' failures to test kits or prosecute offenders are inextricably linked to biases in the criminal justice system and how narratives of being a "responsible" rape survivor promote colorblind ideals that negate racialized women's experiences. Moreover, she attends to the historical and contemporary backdrop of rape kit controversies, tracing Black women's vocal anti-rape activism in the US through the mid-1800s. Interrogating technosocial entanglements thus does not mean abandoning the driving critical impetus for intersectional criminology. Rather, it means modifying our lenses for seeing our worlds so as to expand its anti-essentialist aims. Accepted explanations of social control consistently overlook or underappreciate how ideology, intersectional difference, and technologies of regulation can both conjoin and cleave to (re)produce the parameters and boundaries of everyday life. As technologies of control become embedded parts of our realities, critical attention to materialization is in serious need within criminological theorizing.

\section{Conclusion: Implications for Intersectional Criminological Praxis}

We have attempted to excavate emergent challenges for criminologists studying interlocking systems of oppression, particularly in relation to the rise of systems in which ubiquitous surveillance and data-driven technologies are key components. Intersectional scholars have provided us with important tools to help theorize and work against exclusionary politics, but questions remain regarding the extent to which current applications of intersectionality can aid in deconstructing technosocial infrastructures. We agree with Nash's (2008: 13) claim:

The important insights that identity is complex, that subjectivity is messy, and that personhood is inextricably bound up with vectors of power are only an analytic starting point; it is time for intersectionality to begin to sort out the paradoxes upon which its theory rests in the service of strengthening its explanatory power.

By explicating insights and examples from feminist technoscience, our aim has not been to reject current approaches to intersectional criminology, but to ask if these other perspectives and tools that might support analyses of the shifting structural considerations revealed through authorities' growing reliance on technologies of control.

This article extends our earlier attempts to map efforts that illustrate how and why interconnected dimensions of inequality and social categories of difference beyond their manifestation as identities are important to the study of crime (Henne and Troshynski 2013a). It reflects our continued hope of encouraging others to revisit and (re)evaluate 
debates about the utility of intersectionality as a conceptual framework in relation to how it might be applied to and adapted for diverse criminological objects of inquirywhether they be women, men, individuals labeled as "criminals," victims, and those with in-between and liminal positionalities that do not fit neatly into legible (and often quantifiable) categories. We share Potter's (2013: 316) vision for an "expanded use" of intersectionality "in all forms of inquiry and most certainly in any form of criminology that designates itself as critical." Our concerns are, therefore, not about scaffolding a particular agenda for intersectional criminological inquiry, but about exploring how different intersectional criminologies might unearth interlocking formations of domination and how they come into being. Accordingly, we think of intersectionality as more of an "orientation" than a framework, with its distinguishing features being a critical sensibility that has "developed largely in the context of Black feminist and women of color theoretical and political traditions" (May 2015: 3).

We conclude with a reflection on what these observations suggest in terms of praxis. Following Townsend-Bell (2009), we prioritize two intersectional issues: the recognition of difference and the pursuit of accountability. Furthering Belknap's (2015) call for an activist criminology in the contemporary moment requires us to expand our repertoire to consider the radical hybridity that technosocial relationships yield, especially as they coalesce with (and often as) legal and regulatory actors (see Brown 2006; Shelby 2018a). Criminologists have grappled with related shifts in governance, which others have described as the rise of the "regulatory state" (Braithwaite 2000), in which states exercise power increasingly "through a regulatory framework, rather than through the monopolization of violence or the provision of welfare" (Walby 1999: 123). Surveillance is an outgrowth and an extension of these changes. We have pointed to feminist technoscience as a potentially productive resource for criminologists (and particularly for intersectional criminologists) because it offers a rich body of work that explores how "technoscience, in partnership with global capitalism, generates major historical transformations, including new ways of conceptualizing what it means to be an embodied human subject in a globalized world" (Åsberg and Lykke 2010: 300).

Equipped with these insights, we must ask: Are we, as criminologists, taking steps to ensure that the knowledge we generate does not actually enhance systems of domination? Are we generating research that actively considers changes in mechanisms of social control so as to work against the reproduction of intersectional inequalities? These questions link to longstanding critical criminological criticisms around the violence that criminology can enable and perpetuate (see also Walters 2003). Rather than rehash arguments with which readers will no doubt be familiar, we reiterate an earlier point that Black feminism offers longer-standing modes of querying "the intersections of race, gender, sexuality and class within the context of global colonial capitalism," as well as critical alternatives to knowledges rooted in systems that have valued "global capital organized around colonial capitalism" (Hong 2008: 100, quoted in Henne and Troshynski 2013a: 458). If we are going to examine and counteract systems that are fortifying regimes that are seemingly "colorblind on the surface but... are significantly influenced by pervasive bias in the criminal justice system," as Alexander (2018) suggests, a critical criminological lens informed by intersectionality (as we think we know it or as we thought we knew it) should be our starting point. We must also look to the Black feminists who are already undertaking important work on ubiquitous surveillance and algorithmic oppression for scholarly guidance (e.g., Browne 2010, 2015; Noble 2018), while adapting lessons from feminist technoscience so that we can work toward 
a praxis that is attentive to-and anticipatory of - the particular challenges of living in divergent worlds etched and shaped by technosocial relations.

\section{References}

Ahmed, S. (2008). Imaginary prohibitions: Some preliminary remarks on the founding gestures of the new materialism. European Journal of Women's Studies, 15(1), 23-39.

Alexander, M. (2018). The newest Jim Crow. The New York Times, SR3. November 11.

Arrigo, B. A., \& Bersot, H. Y. (2016). Revolutionizing academic activism: Transpraxis, critical pedagogy, and justice for a people yet to be. Critical Criminology: An International Journal, 24(4), 549-564.

Åsberg, C., \& Lykke, N. (2010). Feminist technoscience studies. European Journal of Women's Studies, 17(4), 299-305.

Association for Women's Rights in Development (AWID). (2004). Gender mainstreaming: Can it work for women's rights? Spotlight, 3. November. https://www.awid.org/sites/default/files/atoms/files/spotl ight_-_gender_mainstreaming_-_can_it_work_for_womens_rights.pdf. Accessed 10 Mar 2019.

Barad, K. (2003). Posthumanist performativity: Toward an understanding of how matter comes to matter. Signs: Journal of Women in Culture and Society, 28(3), 801-831.

Barad, K. (2007). Meeting the universe halfway: Quantum physics and the entanglement of matter and meaning. Durham, NC: Duke University Press.

Barak, G., Leighton, P., \& Flavin, J. (2010). Class, race, gender, and crime: The social realities of justice in America. Lanham, MD: Rowman \& Littlefield.

Belknap, J. (2015). Presidential address: Activist criminology-Criminologists' responsibility to advocate for social and legal justice. Criminology, 53(1), 1-22.

Bell, K. E. (2017). Prison violence and the intersectionality of race/ethnicity and gender. Criminology, Criminal Justice, Law and Society, 18(1), 106-121.

Bernstein, E. (2010). Militarized humanitarianism meets carceral feminism: The politics of sex, rights, and freedom in contemporary antitrafficking campaigns. Signs: Journal of Women in Culture and Society, $36(1), 45-72$.

Binder, A. (1987). Criminology: Discipline or and interdiscipline? Issues in Integrative Studies, 5, 41-67. https://oakland.edu/Assets/upload/docs/AIS/Issues-in-Interdisciplinary-Studies/1987-Volume-05/04_ Vol_5_pp_41_67_Criminology_Discipline_or_Interdiscipline_(Arnold_Binder).pdf. Accessed 10 Mar 2019.

Bowleg, L. (2008). When Black + lesbian + woman $\neq$ Black lesbian woman: The methodological challenges of qualitative and quantitative intersectionality research. Sex Roles: A Journal of Research, 59(5-6), $312-325$.

Braithwaite, J. (2000). The new regulatory state and the transformation of criminology. British Journal of Criminology, 40(2), 222-238.

Brayne, S. (2017). Big data surveillance: The case of policing. American Sociological Review, 82(5), 977-1008.

Britton, D. M. (2000). Feminism in criminology: Engendering the outlaw. The Annals of the American Academy of Political and Social Science, 571(1), 57-76.

Brown, S. (2006). The criminology of hybrids: Rethinking crime and law in technosocial networks. Theoretical Criminology, 10(2), 223-244.

Browne, S. (2010). Digital epidermalization: Race, identity, and biometrics. Critical Sociology, 36(1), $131-150$.

Browne, S. (2015). Dark matters: On the surveillance of Blackness. Durham, NC: Duke University Press.

Campbell, R., \& Fehler-Cabral, G. (2018). Why police "couldn't or wouldn't" submit sexual assault kits for forensic DNA testing: A focal concerns theory analysis of untested rape kits. Law \& Society Review, 52(1), 73-105.

Carbado, D. W. (2013). Colorblind intersectionality. Signs: Journal of Women in Culture and Society, 38(4), 811-845.

Carrington, K., Donnermeyer, J. F., \& DeKeseredy, W. S. (2014). Intersectionality, rural criminology, and re-imaging the boundaries of critical criminology. Critical Criminology: An International Journal, 22(4), 463-477.

Charlesworth, H. (2005). Not waving but drowning: Gender mainstreaming and human rights at the United Nations. Harvard Human Rights Journal, 18(1), 1-18. 
Cho, S., Crenshaw, K., \& McCall, L. (2013). Toward a field of intersectionality studies: Theory, applications, and praxis. Signs: Journal of Women in Culture and Society, 38(4), 785-810.

Collins, P. H. (2000). Gender, Black feminism, and Black political economy. The Annals of the American Academy of Political and Social Science, 568(1), 41-53.

Collins, P. H. (2015). Intersectionality's definitional dilemmas. Annual Review of Sociology, 41, 1-20.

Creek, S. J., \& Dunn, J. L. (2014). Intersectionality and the study of sex, gender, and crime. In R. Gartner \& B. McCarthy (Eds.), The Oxford handbook of gender, sex, and crime (pp. 40-58). Oxford: Oxford University Press.

Crenshaw, K. (1991). Mapping the margins: Intersectionality, identity politics, and violence against women of color. Stanford Law Review, 43(6), 1241-1299.

Crenshaw, K. W. (1988). Race, reform and retrenchment: Transformation and legitimation in antidiscrimination law. Harvard Law Review, 101(7), 1331-1387.

Daly, K. (2010). Feminist perspectives in criminology: A review with Gen Y in mind. In E. McLaughlin \& T. Newburn (Eds.), The SAGE handbook of criminological theory (pp. 225-246). London: Sage.

Dottolo, A. L., \& Stewart, A. J. (2008). "Don't ever forget now, you're a Black man in America”: Intersections of race, class and gender in encounters with the police. Sex Roles, 59(5-6), 350-364.

Dubrofsky, R. E., \& Magnet, S. A. (2015). Feminist surveillance studies: Critical interventions. In R. E. Dubrofsky \& S. A. Magnet (Eds.), Feminist surveillance studies (pp. 1-17). Durham, NC: Duke University Press.

Erez, E., Adelman, M., \& Gregory, C. (2009). Intersections of immigrations and domestic violence. Feminist Criminology, 4(1), 32-56.

Eubanks, V. (2018). Automating inequality: How high-tech tools profile, police, and punish the poor. New York: St. Martins Press.

Fullagar, S. (2017). Post-qualitative inquiry and the new materialist turn: Implications for sport, health and physical culture research. Qualitative Research in Sport, Exercise and Health, 9(2), 247-257.

Gabbidon, S. L., \& Greene, H. T. (2018). Race and crime (5th ed.). New York: Routledge.

Haggerty, K., \& Gazso, A. (2005). Seeing beyond the ruins: Surveillance as a response to terrorist threats. The Canadian Journal of Sociology, 30(2), 169-187.

Haggerty, K. D., \& Ericson, R. V. (2000). The surveillant assemblage. The British Journal of Sociology, 51(4), 605-622.

Hannah-Moffat, K. (2018). Algorithmic risk governance: Big data analytics, race, and information activism in criminal justice debates. Theoretical Criminology. https://doi.org/10.1177/1362480618763582.

Haraway, D. (1991). Simians, cyborgs, and women: The reinvention of nature. New York, NY: Routledge.

Henne, K. (2014). The "science" of fair play in sport: Gender and the politics of testing. Signs: Journal of Women in Culture and Society, 39(3), 787-812.

Henne, K. E. (2015). Testing for athlete citizenship: Regulating doping and sex in sport. New Brunswick, NJ: Rutgers University Press.

Henne, K., \& Troshynski, E. (2013a). Mapping the margins of intersectionality: Criminological possibilities in a transnational world. Theoretical Criminology, 17(4), 455-473.

Henne, K., \& Troshynski, E. (2013b). Suspect subjects: Affects of bodily regulation. International Journal for Crime, Justice, and Social Democracy, 2(2), 100-112.

Henne, K., \& Troshynski, E. (2017). Intersectionality. In A. Brisman, E. Carrabine, \& N. South (Eds.), The Routledge companion to criminological theory and concepts (pp. 316-320). Abingdon, Oxon: Routledge.

Hochman, A. (2018). Racialization: A defense of the concept. Ethnic and Racial Studies. https://doi. org/10.1080/01419870.2018.1527937.

Hong, G. K. (2008). "The future of our worlds": Black feminism and the politics of knowledge in the university under globalization. Meridians: Feminism, race, transnationalism, 8(2), 95-115.

Hudson, B. (2000). Critical reflection as research methodology? In V. Jupp, P. Davies, \& P. Francis (Eds.), Doing criminological research (pp. 175-192). London: Sage.

Jones-Brown, D. (2000). Debunking the myth of officer friendly: How African American males experience community policing. Journal of Contemporary Criminal Justice, 16(2), 209-229.

Josephson, J. (2002). The intersectionality of domestic violence and welfare in the lives of poor women. Journal of Poverty, 6(1), 1-20.

Kennedy, H. (2005). Subjective intersections in the face of the machine. European Journal of Women's Studies, 12(4), 471-487.

King, D. K. (1988). Multiple jeopardy, multiple consciousness: The context of a Black feminist ideology. Signs: Journal of Women in Culture and Society, 14(1), 42-72. 
Law, J. (2004). Matter-ing: Or how might STS contribute? Lancaster: Centre for Science Studies, Lancaster University. http://www.lancaster.ac.uk/fass/resources/sociology-online-papers/papers/law-matter-ing. pdf. Accessed 1 Nov 2018.

Lumsden, K., \& Goode, J. (2018). Public criminology, reflexivity and the enterprise university: Experiences of research, knowledge transfer work, and co-option with police forces. Theoretical Criminology, 22(2), 243-257.

Lupton, D. (2016). Digital companion species and eating data: Implications for theorizing digital datahuman assemblages. Big Data \& Society, 3(1), 1-5.

Lykke, N. (2011). Intersectional analysis: Black box or useful critical feminist thinking technology. In H. Lutz, M. T. H. Vivar, \& L. Supik (Eds.), Framing intersectionality: Debates on a multifaceted concept in gender studies (pp. 207-220). Surrey: Ashgate.

Lynch, M. J., Barrett, K. L., Stretesky, P. B., \& Long, M. A. (2017). The neglect of quantitative research in green criminology and its consequences. Critical Criminology: An International Journal, 25(2), 183-198.

Lyon, D. (2003). Surveillance as social sorting: Computer codes and mobile bodies. In D. Lyon (Ed.), Surveillance as social sorting: Privacy, risk, and digital discrimination (pp. 13-30). London: Routledge.

Magnet, S. A. (2011). When biometrics fail: Gender, race, and the technology of identity. Durham, NC: Duke University Press.

May, V. M. (2015). Pursuing intersectionality, unsettling dominant imaginaries. London: Routledge.

McCall, L. (2005). The complexity of intersectionality. Signs, 30(3), 1771-1800.

Mol, A. (2002). The body multiple: Ontology in medical practice. Durham, NC: Duke University Press.

Monahan, T. (2017). Regulating belonging: Surveillance, inequality, and the cultural production of abjection. Journal of Cultural Economy, 10(2), 191-205.

Moser, I. (2006). Sociotechnical practices and difference: On the interferences between disability, gender, and class. Science, Technology and Human Values, 31(5), 537-564.

Musto, J. L. (2016). Control and protect: Collaboration, carceral protection, and domestic sex trafficking in the United States. Berkeley, CA: University of California Press.

Naples, N. A. (2009). Crossing borders: Community activism, globalization, and social justice. Social Problems, 56(1), 2-20.

Nash, J. C. (2008). Re-thinking intersectionality. Feminist Review, 89, 1-15.

Nash, J. C. (2019). Black feminism reimagined: After intersectionality. Durham, NC: Duke University Press.

Noble, S. U. (2018). Algorithms of oppression: How search engines reinforce racism. New York: NYU Press.

Parker, K. F., \& Hefner, M. K. (2015). Intersections of race, gender, disadvantage, and violence: Applying intersectionality to the macro-level study of female homicide. Justice Quarterly, 32(2), 223-254.

Patton, P. (1994). Metamorpho-logic: Bodies and powers in A Thousand Plateaus. Journal of the British Society of Phenomenology, 25(2), 157-169.

Potter, H. (2013). Intersectional criminology: Interrogating identity and power in criminology research and theory. Critical Criminology: An International Journal, 21(3), 305-318.

Potter, H. (2015). Intersectionality and criminology: Disrupting and revolutionizing studies of crime. London: Routledge.

Puar, J. K. (2007). Terrorist assemblages: Homonationalism in queer times. Durham, NC: Duke University Press.

Puar, J. K. (2017). The right to main: Debility, capacity, disability. Durham, NC: Duke University Press.

Purdie-Vaughns, V., \& Eibach, R. P. (2008). Intersectional invisibility: The distinctive advantages and disadvantages of multiple subordinate-group identities. Sex Roles, 59(5-6), 377-391.

Quinlan, A. (2017). The technoscientific witness of rape: Contentious histories of law, feminism, and forensic science. Toronto: University of Toronto Press.

Richie, B. E. (1996). Compelled to crime: The gender entrapment of battered Black women. New York: Routledge.

Russell-Brown, K. (1998). The color of crime. New York: New York University Press.

Shelby, R. (2018a). Whose rape kit? Stabilizing the Vitullo ${ }^{\circledR}$ Kit through positivist criminology and protocol feminism. Theoretical Criminology. https://doi.org/10.1177/1362480618819805.

Shelby, R. (2018b). Sexual violence, intersectionality, and the "forensic gaze." Paper presented at the annual meeting of the American Society of Criminology on 16 November, Atlanta, Georgia.

Simpson, S. S., \& Gibbs, C. (2006). Making sense of intersections. In K. Heimer \& C. Kruttschnitt (Eds.), Gender and crime: Patterns in victimization and offending (pp. 269-302). New York: New York University Press. 
Singh, R. D. (2010). In between the system and the margins: Community organizations, mandatory charging and immigrant victims of abuse. Canadian Journal of Sociology, 35(1), 31-62.

Sokoloff, N. J. (2004). Domestic violence at the crossroads: Violence against poor women and women of color. Women's Studies Quarterly, 32(2-3), 139-147.

Southern Poverty Law Center. (2016). Hatewatch update: 1094 bias-related incidents in the month following the election. Montgomery, AL. https://www.splcenter.org/hatewatch/2016/12/16/updat e-1094-bias-related-incidents-month-following-election. Accessed 16 December.

Townsend-Bell, E. E. (2009). Intersectional praxis. Paper presented at the annual meeting of the American Political Science Association, Toronto, Ontario.

Trahan, A. (2011). Qualitative research and intersectionality. Critical Criminology: An International Journal, 19(1), 1-14.

Troshynski, E. I. (2017). "Stalked by the state": GPS surveillance technology and sex offender parolees. Kriminologisches Journal, 49(2), 103-119.

Troshynski, E. I., \& Weiner, J. D. (2016). Freak Show: Modern constructions of Ciceronian Monstra and Foucauldian monstrosity. Law, Culture and the Humanities, 12(3), 741-765.

Visher, C. A. (1983). Gender, police arrest decisions, and notions of chivalry. Criminology, 21(1), 5-28.

Wajcman, J. (2010). Feminist theories of technology. Cambridge Journal of Economics, 34(1), $143-152$.

Walby, S. (1999). The new regulatory state: The social powers of the European Union. British Journal of Sociology, 50(1), 118-138.

Walby, S. (2005). Gender mainstreaming: Productive tensions in theory and practice. Social Politics: International Studies in Gender, State \& Society, 12(3), 321-343.

Walters, R. (2003). Deviant knowledge: Criminology, politics, and policy. Cullompton, Devon: Willan.

Whalley, E., \& Hackett, C. (2017). Carceral feminisms: The abolitionist project and undoing dominant feminisms. Contemporary Justice Review, 20(4), 456-473.

Williams, T. (2008). Intersectionality analysis in the sentencing of Aboriginal women in Canada: What difference does it make? In E. Gabham, D. Cooper, J. Krishnada, \& D. Herman (Eds.), Intersectionality and beyond (pp. 95-120). London: Routledge-Cavendish.

Woolgar, S., \& Lezaun, J. (2013). The wrong bin bag: A turn to ontology in science and technology studies? Social Studies of Science, 43(3), 321-340.

Young, V. D. (1986). Gender expectations and their impact on Black female offenders and victims. Justice Quarterly, 3(3), 305-327.

Yuval-Davis, N. (2006). Intersectionality and feminist politics. European Journal of Women's Studies, 13(3), 193-209.

Yuval-Davis, N. (2011). Beyond the recognition and re-distribution dichotomy: Intersectionality and stratification. In H. Lutz, M. T. H. Vivar, \& L. Supik (Eds.), Framing intersectionality: Debates on a multifaceted concept in gender studies (pp. 155-169). Surrey: Ashgate.

Publisher's Note Springer Nature remains neutral with regard to jurisdictional claims in published maps and institutional affiliations. 